\title{
Article
}

\section{Development of expertise in elite and sub-elite British rugby league players: A comparison of practice experiences}

Rothwell, Martyn, Stone, Joseph A., Davids, Keith and Wright, Craig Michael

Available at http://clok.uclan.ac.uk/20189/

Rothwell, Martyn, Stone, Joseph A., Davids, Keith and Wright, Craig Michael (2017) Development of expertise in elite and sub-elite British rugby league players: A comparison of practice experiences. European Journal of Sport Science . pp. 1-9. ISSN 1746-1391

It is advisable to refer to the publisher's version if you intend to cite from the work. http://dx.doi.org/10.1080/17461391.2017.1380708

For more information about UCLan's research in this area go to http://www.uclan.ac.uk/researchgroups/ and search for <name of research Group>.

For information about Research generally at UCLan please go to http://www.uclan.ac.uk/research/

All outputs in CLoK are protected by Intellectual Property Rights law, including Copyright law. Copyright, IPR and Moral Rights for the works on this site are retained by the individual authors and/or other copyright owners. Terms and conditions for use of this material are defined in the policies page.

\section{CLoK}

Central Lancashire online Knowledge www.clok.uclan.ac.uk

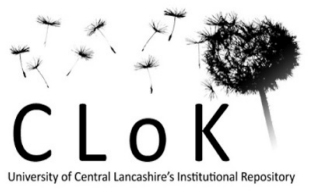




\section{Abstract}

2 Previous studies have investigated how individuals reach an expert level by counting the number of hours engaged in specific practice types. Here we sought to understand and compare the microstructure (e.g. practice tasks undertaken) of these practice hours experienced by elite and sub elite British rugby league players. Semi structured interviews

6 explored the practice experiences of eight international and eight domestic level players. A

7 two-staged thematic analysis was used to interpret the data. The analysis revealed that both player groups experienced a rich and narrow landscape of affordances and were exposed to early diversification of sport experiences during childhood. Differences were identified in domestic level players' experiences of amateur and professional sport, where, episodes of negative developmental environments were reported. International players' practice experiences revealed differences in their professional careers, where, exposure to scenariobased practice and dynamic learning environments were reported. Players' insights were interpreted from an ecological dynamics theoretical framework. These shared insights can support coach educators in designing learning programs that help coaches recognise the skill acquisition and development needs of elite performers in moving between highly structured and highly varied learning experiences, based on the individual needs of an athlete at any one point in time. 


\section{Introduction}

To reach the top in sport will normally require aspiring athletes, at some stage in their career, to access a talent development environment (TDE). These structured performance pathways are now common place across the world, with many countries investing heavily into the identification and development of talent. In the United Kingdom for example, TDE's are now firmly established through the academy system in many team sports. Although common place, the coaching practice within these TDEs has been criticised for adopting traditional teaching and coaching methods, where an overemphasis on direct instruction of athletes, through a technique-focused reproductive-linear coaching style is common (Partington \& Cushion, 2011; Ryan, 2016). Typically, a repreductive-linear coaching style is highly structured and advocates the rehearsal of optimal movement templates through task decomposition and drill-based practices. For these reasons, the pre-dominant 'repreductive' 'linear' style in sport pedagogy has been criticised as running counter to the methodological approach needed to enhance expertise in competitive athletes (Moy, Renshaw, Davids \& Brymer, 2016Davids, Button, \& Bennett, 2008). In addition, TDEs that adopt these coaching approaches have been criticised for being too structured resulting in the 'over-systematization' of developing athletes (Renshaw, Oldham, Glazier \& Davids, 2004), leading to the effectiveness of such environments being questioned (Renshaw, Davids, Phillips \& Kerhervé, 2012).

In contrast, an ecological dynamics perspective considers performers as complex adaptive systems and examines the emergence of sport performance at the level of the performer-environment relationship (Araújo, Davids, \& Hristovski, 2006). From this perspective, expert sport performance is developed when performers are exposed to, and can interact with, key task and environmental constraints that promote exploratory behaviours to search for specifying information sources (Davids, Button, Araújo, Renshaw \& Hristovski, 
2006). Specifying information supports the utilisation of affordances to positively constrain movements, whereas non-specifying information is less relevant to the performer environment relationship (Jacobs \& Michaels, 2002). Affordances are opportunities for action presented in our socio-cultural practices (Rietveld \& Kiverstein, 2014), and are related to an individual's ability to use available information to regulate and organise actions to develop adaptable behaviours that supports expert performance (Esteves, De Oliveira, \& Araújo, 2011).

Considering the challenges associated with the linear reproductive-coaching style in TDEs, and because previous research has identified that coaching culture and practice philosophy influence practice task design (Ford, Yates \& Williams, 2010). It would be beneficial to investigate how coaching culture and-practice philosophy might have influenced the design of practice tasks and learning programmes that lead to expertise (Helsen, Starkes, \& Hodges, 1998), before the introduction of current academy programs. A sport that provides a suitable research opportunity and lacks research into the development of player-expertises practice experiences, is rugby football league. Little or no research has explored the development activities of British expert rugby league players prior to the introduction of the systematised academy structure that was introduced between 2001 and 2002 . It could also be considered that the sport has a dominant reproductive linear coaching approach because formal coach education programs in the sport promote the development of optimal movement templates (e.g. when learning the '6 O'clock pass' performers are required to: (1) point the ball to 6 O'clock, and (2), pass over the front foot) (Rugby Football League Level 2 Coaching Manual, 2014).

Therefore, the aim of this study was to compare the perceptions of pre academy elite and sub elite British rugby league players' practice histories, in order to identify differences 
in the interacting range of environmental and practice task constraints that they experienced

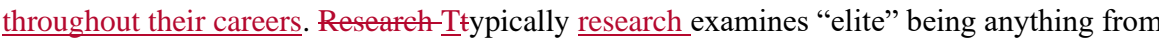
international to semi professional standard (Swann, Moran, \& Piggott, 2015). Here we wanted to compare "the best" professional (i.e. international) against other professional players. Unlike previous work that has shown differences between professional performers and then amateurs, where you would expect a large difference in performance, we focused on

81 the changes which might take players from domestic to international standard. It was expected that findings would provide insights into the effective design of practice programmes to facilitate the acquisition of expertise and talent in sport.

\section{Methods}

$86 \quad$ Research Design

87 In line with previous research designs that have aimed to construct or develop knowledge about individuals and the social world they reside in, qualitative inquiry in the form of semi-strucutred interviews was adopted (Sparkes \& Smith, 2014). The design was considered to be most appropriate for achieving our philosophical aim of testing a priori hypotheses of the value in adopting an ecological dynamics rationale to understand expertise acqusition in sport (Markula \& Silk, 2011). To achieve this purpose we connected with epistemological constructionism and ontological relativism to inform a post-positivism research paradigm (Smith \& Sparkes, 2016).

Participants

Sixteen past or present professional British rugby league players were interviewed for the study. Eight were domestic level (e.g. played in the British Super League or

99 Championship competitions) players (4 present and 4 past) and eight were domestic level 
players who had gone on to represent their countries internationally (5 present and 3 past).

Domestic level players were catorgorised as sub elite and international players were

catorgorised as elite. At the time of the interviews the mean player age was 33 (range 30 to

36) years, the range was selected to minimize effects of variations in age on participant

perceptions. Institutional ethical approval was granted with all participants providing

informed consent.

\section{$\underline{\text { Data Collection }}$}

The development of the semi-strucutred interview guide was informed by theory

(Hanton \& Jones, 1999; Cote, Ericsson, \& Law, 2005), and the authors a priori knowledge of the subject area. The guide ensured that each participant was asked the same set of $\underline{\text { fundamental questions to invite participants to lead the conversation, elaborate, and discuss }}$ their unique experiences (Patton, 2002).The interview guide was piloted on a sample of three retired sports professionals. Following the pilot, a review and debrief was carried out with the coauthors and minor modifications were made to the narrative. All interviews were conducted face to face by the lead author and lasted an average of $40 \pm 16$ minutes. Of specific interest was the participants' practice experiences. Probe questions were used to encourage participants to expand on responses and provide articulated accounts. During data collection all interviews were audio recorded in their entirety and transcribed verbatim.

\section{Data analysis}

A two-staged thematic analysis (Braun \& Clarke, 2006) was employed to analyse collected data. The first coding stage followed deductive analysis on the themes set out from the onset: deliberate play, amateur sport, and professional sport. Once data were categorised into the three areas, an inductive thematic analysis was employed to elicit relevant 
information. Raw data themes were identified because they captured something important about the data in relation to the research aim. These themes were then refined, named and organised into groups of responses to create lower and higher order themes, and four dimensions.

\section{Research Quality and Rigor}

Although rigour in qualitative research has instigated a multitude of scholarly activity

of late (See, Smith \& McGannon, 2017), several steps were taken to ensure trustworthiness of the data. First, purposeful sampling was employed (Patton, 2002) with specific criteria (age and playing status) used to ensure that participants were appropriate for the study. Second, member checks were achieved through sending copies of transcripts to a sample of four participants, together with a summary of the results. All the players confirmed that transcriptions and results were a true reflection of their practice experiences. Finally, in line with methods employed by Sparkes and Partington (2003), the second and fourth author acted as a critical friend and questioned interpretations made at each stage.

\section{Results and Discussion - A Comparison of Practice Histories and Implications for}

\section{Practice Design}

The thematic analysis of the data highlighted a total of 32 lower order themes, 13 higher order themes, and four dimensions. The four dimensions include, Affordances, Environmental Constraints: Social, and Early Diversification (international and domestic players), and Dynamic Learning Environments (international players) (see Figure 1 and 2). 


$$
\text { ***Insert Figure } 2 \text { here } * * *
$$

Figue 2. Thematic map of international players

\section{Affordances}

Both player groups discussed opportunities for action during their experiences of deliberate play, amateur sport, and professional sport. Here, we have used a Gibsonian concept and termed these opportunities for action as affordances (Gibson, 1979). This dimension was deemed important because it can start to provide insights for coaches into how to create a resourceful practice environment to enhance a players' responsiveness to available affordances (Bruineberg \& Rietveld, 2014). Therefore, the results and discussion for this dimension will only focus on experiences of amateur and professional sport, because coaches will typically not influence deliberate play activity. Within the dimension of affordances, two higher order themes were identified across both player groups; these were narrow landscape of affordances (limited opportunities) and rich landscape of affordances (increased opportunities).

Players' accounts of amateur sport revealed experiences of narrow landscape of affordances (drills) and rich landscape of affordances (small sided rugby games). Player interviews provided further insights into the characteristics of drills, where set actions were prescribed by the coach, practice task decomposition was common, and exposure to team runs or sub phases of play did not include opposition players. These narrow performance landscapes are problematic for sport performers because they do not faithfully represent game conditions (Pinder, Davids, Renshaw, \& Araújo, 2011b), at the expense of providing realistic learning conditions that are rich in relevant information that support collective decision making (Fajen, Riley, \& Turvey, 2009). Intuitively, players' felt that this practice type was 
counterproductive to their development, providing negative views in regards to its efficacy. A

player discusses his views on this practice type:

"It was more drills for drill sake type of thing, going up and hitting a pad like nothing that's really going to prepare you for rugby I don't think. Going up and hitting one of those pads and knocking it down and coming back has absolutely nothing to do with rugby”. (International Player 4)

In comparison, coach led small sided rugby games provided players with a rich landscape of affordances. The theory of affordances highlights the benefits of these small sided games, where perceiving affordances from a landscape rich in specifying information allowed players' to prospectively control their behaviour (e.g. future information about whether or not an attacker in rugby league will beat a defender if current foot speed and running angle are maintained) (Turvey \& Shaw, 1995), and allowed for perception action coupling to support emergent performance behaviours (Passos, Cordovil, Fernandes, \&

Barreiros, 2012). These important factors are exemplified through the practice landscape this player experienced in relation to defensive and support players, and the related decision making opportunities dependant on the actions of the defence (e.g. pass, run, or kick):

"He would get lots of games that would be getting the defence to move around and playing then what's in front of you, and getting me to get runners running in behind. I think the impact that had on me was understanding the benefits of that and the bigger impact that has on the game. I think it is rather than just being told to do something for the sake of doing something, it's highlighting in the player's head you know the reasons and what's going to happen from that". (Domestic player 1)

Players' accounts of professional sport revealed similarities during their practice histories, with experiences of narrow and rich landscape of affordances discussed. Practice tasks that presented them with a narrow landscape of affordances, were described through experiences of drills, deliberate practice, and structured game plans. Players regularly discussed the consequences of structured game plans on their ability to play the game and the 
influence on practice design, a player discusses the structured culture of the game and how it influenced young players' ability to become perceptually attuned to the affordance landscape:

"the game has gone really structured with all these block plays and that's something we are now trying to get back into them, we've noticed in some of the young kids you ask them to do real basic things like we were saying about the games and they don't do it. Yet they could be a half back, this kid he's the best half back in the country but you put three defenders in front of him and he's looking to put a play on, rather than run at them and just beat them". (International Player 6)

A difference in international players' practice experiences of professional sport, which may provide insights into why they progressed from domestic to international level, was scenario based practice tasks. Scenario based practice presented players' with a performance landscape that invited specific actions required to engage effectively with the performance environment through exposure to specific and relevant information (Araújo \& Davids, 2011).

Consider the affordances this player experienced during practice in relation to teammates, opposition players, and pitch orientation:

"we had like scenario training and we got to where we had to score a try on the last play and automatically we went to kicking the ball in the air, and he (coach) went right I'd knew you'd do that. He said, 'whatever you do now if we need a try in the last play you do not kick it', he said 'because then the ball becomes the object', he said 'when you keep the ball in hand they have 13 players to take care of, once the ball goes in the air they just have the ball to take care of so you move it through the hands no matter what you keep the ball alive'. And we never knew it was going to come down to a playoff game but it came down to that and we ended up scoring from keeping the ball alive". (International Player 7)

These findings provide useful insights for coaches when designing learning tasks, who should aim to provide athletes with opportunities to attune their behaviour to specifying information to support and regulate actions (Araújo \& Davids, 2015). This means that coaches should go beyond playing small-sided games (although beneficial) and instead ensure that game based activity accurately samples the performance environment and related affordances (Withagen, de Poel, Araújo \& Pepping, 2012), leading to greater transfer in sports which are dynamic, unpredictable, and fast paced. 


\section{Environmental Constraints: Social}

Within this dimension higher order themes of positive experiences and supportive environment were experienced by both player groups, and negative experiences were reported by domestic players only. During deliberate play a supportive environment was reported by both player groups, where family and friends encouraged and facilitated deliberate play activities. Both player groups reported positive experiences of amateur rugby, but domestic players' accounts also revealed episodes of negative developmental experiences. Although domestic players views on the coach were positive, consistent with previous research into negative experiences of sport (Balaguer et al. 2012), domestic players perceived negative experiences because of limited development and decision-making opportunities during practice. In comparison, domestic and international players' positive experiences of amateur sport were characterised by positive relationships, having fun, and not feeling pressure during practice or competitive matches. A player provides an example:

"I just remember them being good blokes, I never remember being under any pressure from the coaches. I always remember it being fun and quite a few good players came out of those teams. Then at 16s I just remember it being good fun I don't ever remember feeling under pressure, apart from the pressure I put myself under because I wanted to do well in the game". (Domestic Player 8)

This player's account demonstrates the importance of coaches creating a positive social context to support psychosocial needs and motivation (Vallerand, 2001). In addition, coaches who provide practice settings that provide positive perceptions are likely to develop healthy coachathlete relationships, leading to athlete enthusiasm, creating a desire to learn, and positively influencing sport enjoyment leading to sustained participation (Cote \& Salmela, 1996). Domestic players' accounts of negative developmental experiences during professional sport practice revealed a feeling that the prioritisation of physical conditioning over tactical and skill development hindered their progression as professional players. A player provides an example: 
2012).

"we'd train 4 or 5 nights a week, Monday would be a bit rehab and light weights to get the lactic acid out, Tuesday would a conditioning session, Wednesday would be weights and speed work, Thursday would be game specific so run through your plays and what ever you did and Friday would be a team run half an hour done. Nobody enjoyed it for the way he ran things, I wouldn't say it improved me as a player" (Domestic Player 3).

Conversely, practice experiences that included game-related practice, freedom to play, and positional specific coaching, were considered factors that supported their development as professional players. These findings highlight the importance of coaches designing practice tasks, not only to support the skill demands of performers, but also the psychological processes to support task engagement and player autonomy, leading to greater levels of motivation and

\section{Early Diversification}

International and domestic players' reported engagement in multisports during childhood, where engagement in invasion games, striking and fielding games, and net and wall games was common. Exposure to a wide range of sports during childhood has been termed early diversification (Côté, Lidor, \& Hackfort, 2009). Players reports of playing other sports with friends and siblings was common, street games were also highlighted as a common pastime for both player groups, this play activity was described as games organised and played with friends or siblings that were not considered a traditional sport. Players' also reported playing other sports in more formal organised settings during childhood, with sports such as football, taekwondo, athletics, rugby union, and cricket played regularly. Previous studies have identified that exposure to early diversification has creativity (Memmert, Baker, \& Bertsch, 2010), physical fitness and gross motor coordination (Fransen et al. 2012), and motivational benefits (Côté, Lidor, \& Hackfort, 2009). Players' perceptions of early 
diversification were positive, suggesting that the unstructured nature of early diversification may have shaped the way they played as a professional player:

"Until you think about it you don't really think about what you did as an 8 or 10 year old ....but when you do look you had the ball in your hand and you're playing unstructured and maybe that did play a little part in the way I became as a player in the professional game. Where I never really liked too much structure in the way that I played the game at professional level, so you kind of look back now and with this chat .....then maybe it did shape the way I played the game as a professional a little bit". (Domestic Player 5)

Although coaches may not be able to influence young sport performers sporting choices, and may be under pressure to maintain participation rates in their sport. These findings should challenge coaches to design practice experiences that provide young sports participant's opportunities to engage in diverse and functional movement solutions during practice, rather than overemphasising the development of rigid movement templates in one sport.

\section{Dynamic Learning Environments}

International players experienced dynamic learning environments across all practice settings, within this dimension two higher order themes of autonomous learning and athlete centred learning were identified. The dimension of dynamic learning environments described frequently changing practice environments that required players to continuously co-adapt to task and environmental constraints. Through the higher order theme of autonomous learning, players engaged in designing practice tasks and problem solving. An ecological dynamics analysis of these experiences highlights how international players' were provided with opportunities to develop a functional relationship with the performance environment to support expertise (Araújo \& Davids, 2011). To enhance this important relationship coaches must provide athletes with opportunities to continually co-adapt their behaviour to changing task and environmental constraints to maintain their effectiveness during performance 
conditions (Passos, Araujo \& Davids, 2016). This is exemplified by this players experiences of deliberate play, where playground rules presented opportunities to play against different ability and older players:

"You worked it out for yourself, on the handball thing there were people who were better than others.........It wasn't just one on one it were like 8 or 10 squares and you just worked your way up when people get knocked out and were rotated to the bottom. People were good at it so you had to learn that game, but not like coaching you just watched what people did". (International Player 4)

Under the higher order theme of athlete-centred learning, players experienced guided discovery during amateur sport, and exploration and task constraints during professional sport. Accounts of professional sport revealed coaching philosophies and practice tasks that encouraged exploration during involvement in the practice setting. Exploratory activity is important for athletes because it can help them to "adequately solve any emerging motor problem correctly, quickly, rationally, and resourcefully" (Bernstein,1967, p.228). This is exemplified by a players experience of a practice task constraint designed to support their search for a movement solution to the skill of tackling:

"you know with tackle technique he'd have you tackling holding tennis balls so you couldn't grab and stuff like that. We'd never done that kind of stuff before. He used to put plastic ties between your ankles so your feet couldn't get too far apart in D (defence), so to keep your feet closer together so you didn't get splayed so you didn't get beat back on your inside" (International Player 7).

These findings highlight the importance of coaches continually redesigning learning tasks to improve the quality of co-adaptations during practice, to support players in exploring functional movement solutions to help them achieve positive outcomes to support effective performance.

\section{Conclusion}


Here, we compared pre academy elite and sub elite British rugby league players' practice histories, in order to identify differences in the interacting range of environmental and practice task constraints that they experienced throughout their careers. The findings suggest that insights from ecological dynamics provide a suitable theoretical framework to guide coaches in the design of practice environments that should consider the physical, psychological, emotional and social dimensions of expertise acqusition. This is evidenced in domestic players' negative development experiences that could be considered detrimental to the development of their motivational and performance behaviours. In addition, international players' insights into scenario based practice and dynamic learning environments highlight the importance of providing specifying information through a rich landscape of affordances to support and regulate actions. Where the emergence of an adaptive functional relationship with the performance environment should be seen as an important part of expertise acqusition. A limitation of this study is the use of retrospective interviews to investigate the microstructure of practice, although an imperfect tool, their validity is acknowledged.

Therefore, future work could consider adopting quantifiable variables to strucutre systematic observations of the microstructure of practice designs.

\section{References}

Alvarez, M. S., Balaguer, I., Castillo, I., \& Duda, J. L. (2012). The coach created motivational climate and young Athletes' well-being and intentions to continue participation. Journal of Clinical Sport Psychology, 6, 166-179.

Araújo, D., \& Davids, K. (2011). What Exactly is Acquired During Skill Acquisition? Journal of Consciousness Studies, 18(3), 7-23.

Araújo, D., \& Davids, K. (2015). Towards a theoretically - driven model of correspondence between behaviours in one context to another: Implications for studying sport performance. International Journal of Sport Psychology, 46, 268-280. 
Araújo, D., Davids, K., \& Hristovski, R. (2006). The ecological dynamics of decision making in sport. Psychology of Sport and Exercise, 7, 653-676.

Balaguer, I., González, L., Fabra, P., Castillo, I., Mercé, J., \& Duda, J. L. (2012). Coaches' interpersonal style, basic psychological needs and the well and ill-being of young soccer players: A longitudinal analysis. Journal of Sports Sciences, 30(15), $1619-1629$.

Bernstein, N. A. (1967). The control and regulation of movements. London: Pergamon Press.

Braun, V., \& Clarke, V. (2006). Using thematic analysis in psychology. Qualitative Research in Psychology, 3(2), 77-101.

Bruineberg, J., \& Rietveld, E. (2014). Self-organization, free energy minimization, and optimal grip on a field of affordances. Frontiers in Human Neuroscience, 8(599), $1-14$.

Côté, J., Ericsson, K. A., \& Law, M. P. (2005). Tracing the development of athletes using retrospective interview methods: a proposed interview and validation procedure for reported information. Journal of Applied Sport Psychology, 17(1), 19-23.

Côté, J., \& Salmela, J. (1996). The organizational tasks of high performance gymnastic coaches. The Sport Psychologist, 10, 247-260.

Côté, J., Lidor, R., \& Hackfort, D. (2009). To Sample or to specialize? Seven postulates about youth sport activities that lead to continued participation and elite performance. International Journal of Sport and Exercise Psychology, 9, 7-17.

Davids, K., Button, C., Araứjo, D., Renshaw, I., \& Hristovski, R. (2006). Movement models from sports provide representative task constraints for studying adaptive behavior in human movement systems. Adaptive Behavior, 14(1), 73-95.

Davids, K., \& Araújo, D. (2010). The concept of ‘Organismic Asymmetry' in sport science. Journal of Science and Medicine in Sport,13(6), 633-640.

Esteves, P., Oliveira, R., \& Araújo, D. (2011). Posture-related affordances guide attacks in basketball. Psychology of Sport and Exercise, 12, 639-644. doi.org/10.1016/j.psychsport.2011.06.007

Ericsson, K., Krampe, R., Tesch-Romer, C. (1993). The role of deliberate practice in the acquisition of expertise performance. Psychological Reviews, 100(3), 363-406.

Fajen, B. R., Riley, M. A., \& Turvey, M. (2009). Information, affordances, and the control of action in sport. International Journal of Sport Psychology, 40, 79-107. 
Ford, P. R, Yates, I., \& Williams, A., M. (2010). An analysis of practice activities and instructional behaviours used by youth soccer coaches during practice: exploring the link between science and application. Journal of Sports Science, 28, (5), 483-495.

Fransen, J., Pion, J., Vandendriessche, J., Vandorpe, B., Vaeyens, R., Lenoir, M., \& Philippaerts, R. (2012). Differences in physical fitness and gross motor coordination in boys aged 6-12 years specializing in one versus sampling more than one sport. Journal of Sports Sciences, 30(4), 379-386.

Gibson, J. J. (1979). The theory of affordances. In R. E. Shaw \& J. Bransford (Eds.), Perceiving, acting, and knowing: Toward an ecological psychology (pp. 67-82). Hillsdale, NJ: Lawrence Erlbaum Associates.

Hanton, S., \& Jones, G. (1999). The acquisition and development of cognitive skills and strategies: Making the butterflies fly in formation. The Sport Psychologist, 13, 1-21.

Helsen, W. E., Starkes, L., \& Hodges, N. (1998). Team sports and the theory of deliberate practice. Journal of Sport \& Exercise Psychology, 20, 12-34.

Hodges, N. J., \& Franks, I. M. (2004). Instructions, demonstrations and the learning process: creating and constraining movement options. In: A. M. Williams \& N. J. Hodges (Eds.), Skill acquisition in sport: research, theory and practice (pp.145-174). Abingdon, Oxon: Routledge.

Jacobs, D. M., \& Michaels, C. F. (2002). On the paradox of learning and realism. Ecological Psychology, 14(3), 127-140.

Memmert, D., Baker, J., \& Bertsch, C. (2010). Play and practice in the development of sportspecific creativity in team ball sports. High ability studies, 21(1), 3-18. doi: 10.1080/13598139.2010.488083

Moy, B., Renshaw, I., Davids, K., \& Brymer, E. (2016). Overcoming acculturation: physical education recruits' experiences of an alternative pedagogical approach to games teaching. Physical Education and Sport Pedagogy, 21(4), 386-406.

Partington, M., \& Cushion, C. J. (2011). An investigation of the practice activities and coaching behaviours of professional top- level youth soccer coaches. Scandinavian Journal of Medicine and Science in Sport. 23(3), 374-382. doi: 10.1111/j.16000838.2011.01383.

Passos, P., Cordovil, R., Fernandes, O., \& Barreiros, J. (2012). Perceiving affordances in Rugby Union. Journal of Sport Sciences, 30(11) 1175-1182. 
Passos, P., Araújo, D., \& Davids, K. (2016). Competitiveness and the Process of Coadaptation in Team Sport Performance. Frontiers in Psychology, 7(1562), doi: 10.3389/fpsyg.2016.01562

Patton, Q. (2002). Qualitative research and evaluation methods (3rd ed.). Thousand Oaks, CA, Sage.

Pinder, R. A., Davids, K., Renshaw, I., \& Araújo, D. (2011b). Representative learning design and functionality of research and practice in sport. Journal of Sport \& Exercise Psychology, 33(1), 146-155.

Renshaw, I., Davids, K., Phillips, E., \& Kerhervé, H. (2012). Developing talent in athletes as complex neurobiological systems. In J. Baker S. Cobley \& J. Schorer (Eds.), Talent Identification and Development in Sport: International Perspectives (pp. 6480). Abingdon, Oxon: Routledge.

Renshaw, I., Oldham, T., Glazier, P., \& Davids, K. (2004). Why applied sport scientists need a theoretical model of the performer. The Sport and Exercise Scientist, 24, 1.

Rietveld, E., \& Kiverstein, J. (2014). A rich landscape of affordances. Ecological Psychology, 26, 325-352.

Rugby Football League. (2014). Certificate in Coaching Rugby League Level 2. Leeds: Coachwise Ltd.

Ryan, D. (2016, January 21). Rugby union's rigid academies risk stifling players' freedom to enthrall. The Guardian. Retrieved from https://www.theguardian.com/sport/2016/jan/21/rugby-union-academies-playersfreedom

Sparkes, A. C., \& Partington, S. (2003). Narrative practice and its potential contribution to sport psychology: The example of flow. The Sport Psychologist, 17(3), 292-317.

Swann, C., Morgan., \& Piggott, D. (2015). Defining elite athletes: Issues in the study of expert performance in sport psychology. Psychology of Sport and Exercise, 16(1), 314.

Turvey, M. T., \& Shaw, R. E. (1995). Toward an ecological physics and a physical psychology. In R. Solso \& D. Massaro (Eds.), The science of the mind: 2001 and beyond (pp. 144-169). Oxford: Oxford University Press.

Vallerand, R. J. (2001). A hierarchical model of intrinsic and extrinsic motivation in sport and exercise. In G.C. Roberts (Eds.), Advances in motivation in sport and exercise (pp. 263-320). Champaign, IL: Human Kinetics. 
510 Withagen, R., de Poel, H. J., Araújo, D., \& Pepping, G. J. (2012). Affordances can invite behavior: Reconsidering the relationship between affordances and agency. New Ideas in Psychology, 30(2), 250-258. 